\title{
PHENOTYPIC DIVERSITY IN WILD Helianthus annuus FROM ARGENTINA
}

\author{
Presotto, A. ${ }^{*} 1,2$, Cantamutto, M. ${ }^{1,3}$, Poverene, M. ${ }^{1,2}$, Seiler, G. ${ }^{4}$
}

${ }^{1}$ Department of Agronomy, Universidad Nacional del Sur,

8000 Bahia Blanca, Argentina

${ }_{2}^{2}$ Centro de Recursos Naturales Renovables de la Zona Semiárida

(CERZOS-CONICET)

${ }^{3}$ Centro UdL-IRTA, Lleida, Cataluña, Spain

${ }^{4}$ USDA-ARS Northern Crop Science Laboratory, P.O. Box 5677 Fargo,

ND 58105 USA

Received: July 21, 2008

Accepted: June 02, 2009

\section{SUMMARY}

Wild Helianthus annuus populations naturalized in central Argentina have spread since their introduction from the center of origin in North America. Phenotypic characterization based on 45 morphological and phenological descriptors of nine populations from different geographic regions of Argentina and 17 populations from the USA provided by the US Department of Agriculture germplasm bank at Ames, Iowa, was obtained by growing populations in an experiment field. Wild populations from Argentina reflected part of the phenotypic variability of populations from the center of origin, but showed adaptation to local conditions which allows differentiation between populations from each continent. All traits showed a continuous range, with majority of extreme values occurring in populations from North America. The populations that showed similarities for one group of descriptors differed in other traits, revealing the existence of different phenotypes. Helianthus annuus populations established in Argentina could be considered a differentiated genetic resource, containing new combinations and traits absent in North American populations, such as the life cycle length in the Diamante population of 180 days and longer, the longest of any population studied.

Key words: adaptation, morphology, naturalized, phenology, sunflower, variability

\section{INTRODUCTION}

The genus Helianthus (Asteraceae) is comprised of 51 species native to North America, a few of which have been disseminated worldwide as ornamentals and food crops (Heiser, 1954; Seiler and Rieseberg, 1997; Schilling, 2006). In Argen-

* Corresponding author: Phone: 54291 4595102; Fax: 54291 4595127;

e-mail: apresotto@uns.edu.ar 
tina, a wild ecotype of Helianthus annuus L. was introduced as forage crop in the 1940s which became the basic genetic material for current naturalized Argentine populations (Bauer, 1991). Sixty years after the intentional introduction, this wild species has spread over extended areas in central Argentina (Poverene et al., 2002).

Wild $H$. annuus constitutes a genetic resource easily transferable to the sunflower crop (Burke et al., 2002; Maxted et al., 2006), providing genes for disease resistance (Putt and Sackston, 1957), oil quality (Seiler, 1983), and herbicide tolerance (Al-Khatib et al., 1998). Argentine wild Helianthus merit interest because its adaptation covers a wide range of agro-ecological conditions (Cantamutto et al., 2008) and their value as a genetic resource is unknown.

Despite the advances in molecular techniques, the level of differentiation detected by neutral genetic markers may not match with what is seen for quantitative traits, making the latter more important for study in cultivated species (Soleimani et al., 2007; Bhattacharjee et al., 2007; Hu et al., 2007; Rawashdeh et al., 2007).

We hypothesize that wild Helianthus annuus populations naturalized in Argentina possess enough genetic diversity to differentiate between them and with the populations from the center of origin. This research will show that naturalized Argentine populations correspond to the wild form of the species and contain high phenotypic variability, which justifies their preservation as a biodiverse genetic resource.

\section{MATERIALS AND METHODS}

Wild germplasm from Argentina consists of nine representative Helianthus annuus populations from different geographic regions (Table 1). Wild germplasm from North America was represented by 17 populations provided by the United States Department of Agriculture (USDA), Agricultural Research Service (ARS), North Central Regional Plant Introduction Station, Ames, Iowa, USA. States where they were collected and passport numbers are: Arizona (AZ) PI 468571, California (CA) PI 468580, Colorado (CO) PI 468621, Illinois (IL) PI 435540, Indiana (IN) PI 468633, Iowa (IA) PI 597901, Kansas (KS) PI 586851, Montana (MT) PI 586821 , Nebraska (NE) PI 586867 Nevada (NV) PI 468596, New Mexico (NM) PI 468537, North Dakota (ND) PI 586807, Oklahoma (OK) PI 468483, South Dakota (SD) PI5 86835, Texas (TX) PI 468504, Utah (UT) PI 468607, and Wyoming (WY) PI 586824 (for more information see: www.ars-grin.gov/cgi-in/npgs/acc/display.pl? 1080516).

The wild populations were grown in a common garden at the Agronomy Department, Universidad Nacional del Sur, Bahia Blanca, Argentina (38 $41^{\prime} 38^{\prime \prime} \mathrm{S}$, $\left.62^{\circ} 14{ }^{\prime} 53^{\prime \prime} \mathrm{W}\right)$. Seed dormancy was overcome by maintaining seeds in germination paper in a wet chamber at $5^{\circ} \mathrm{C}$ for one week (ISTA, 2004). After taproot emergence, seedlings were transferred to $28 \times 54 \mathrm{~cm} \mathrm{200-cell} \mathrm{plastic} \mathrm{trays.} \mathrm{Seedlings} \mathrm{were}$ 


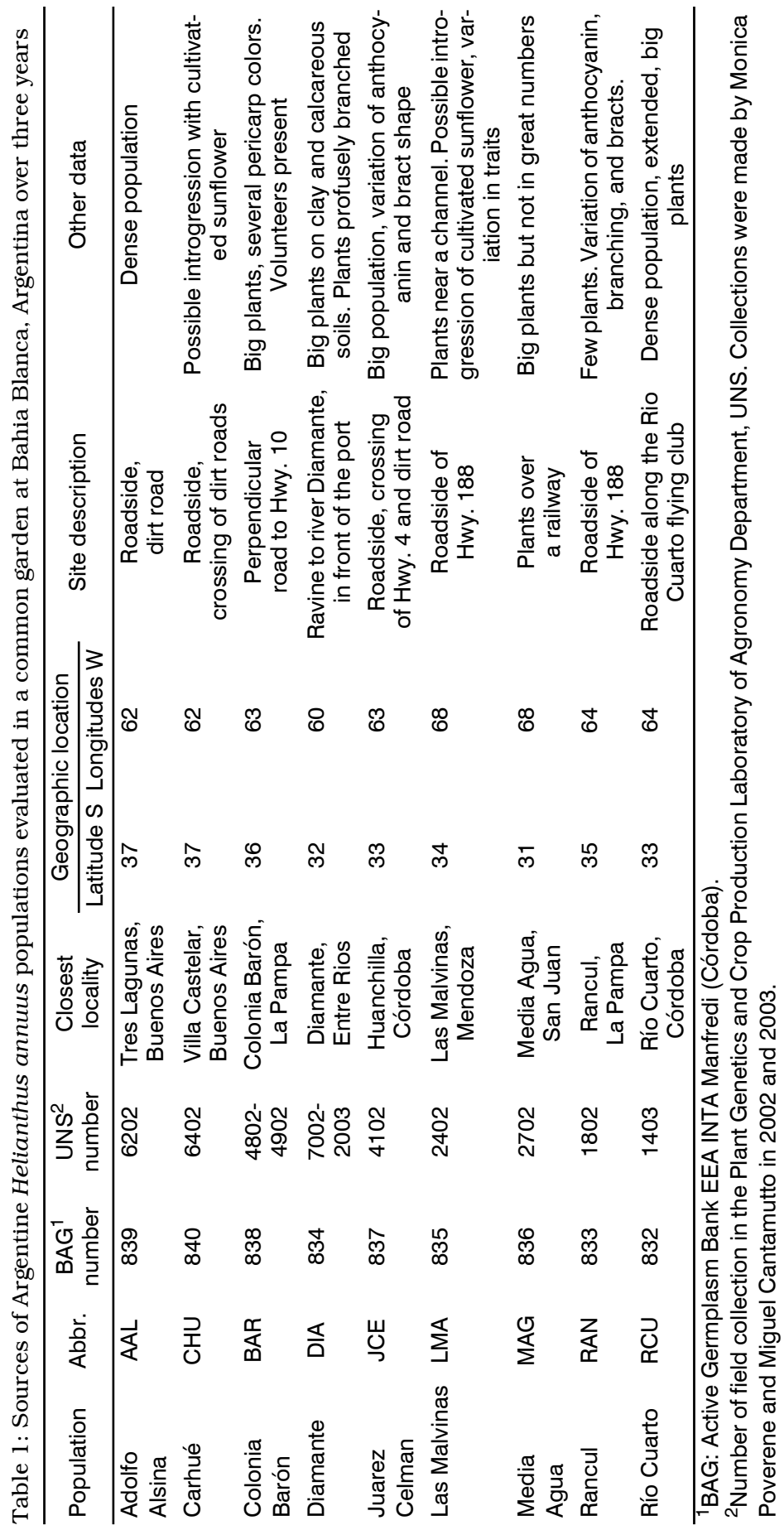


grown for 30 days in the greenhouse under natural light at $20-25^{\circ} \mathrm{C}$. They were then transplanted to the field.

Each year the plants were placed in rows separated $2.10 \mathrm{~m}$ with a $0.25 \mathrm{~m}$ separation between individuals (equivalent plant population of 19.047 plants $^{-1} \mathrm{a}^{-1}$ ) randomized in the plot. Populations consisting of more than 30 plants were split in two groups. Extreme rows and external plants were omitted from the data collection. The plots were irrigated using a pressurized system to maximize plant growth. Data were collected during three successive summer seasons, from 2004 to 2006, with each population evaluated for at least two years. In total, 586 individuals were evaluated, including at least 20 from each of the studied populations, except four accessions which had only 14 to 18 individuals. Seed collected from the original populations were used the first season of evaluation. Seeds used for subsequent evaluations were generated through controlled pollinations. To exclude natural pollinators, polyamide bags were placed over the heads before ray flowers emergence (equivalent to the R4 stage of Schneiter and Miller, 1981). Bulked pollen from sib plants of the same population was applied by hand 2 to 3 times during a 4- to 7-day period after bagging until the end of flowering at the R6 stage. For seed regeneration, 20 to 30 maternal plants were used, except in the four populations with fewer individuals.

Table 2: Descriptors used for characterization of wild sunflower populations grown in a common garden

\begin{tabular}{|c|c|c|c|}
\hline Abbreviation & Descriptors (category, units) & Source $^{3}$ & Type $^{4}$ \\
\hline \multicolumn{4}{|c|}{ Plant Characters } \\
\hline PUBTA & Stem pubescence at maturity (presence or absence) & M & At \\
\hline RAMI & $\begin{array}{l}\text { Branching type (no branching, basal branching, apical branching, } \\
\text { full branching) }\end{array}$ & A & At \\
\hline ALT & Plant height $(\mathrm{cm})$ & $\mathrm{A}$ and $\mathrm{M}$ & Q \\
\hline DIAMTA & Stem diameter at mid-height $(\mathrm{cm})$ & M & Q \\
\hline CAPRIN & Presence of main head (presence, absence) & A & At \\
\hline INCLCAP & Head position $\left({ }^{\circ}\right)$ & M & Q \\
\hline NUCAP & Number of heads $(n)$ & A & Q \\
\hline \multicolumn{4}{|c|}{ Leaf Characters } \\
\hline ANHOJ & Leaf width $(\mathrm{cm})$ & M & Q \\
\hline LARHOJ & Leaf length (cm) & A & Q \\
\hline TAMHOJ & Leaf size (width $x$ length, $\mathrm{cm}^{2}$ ) & A & Q \\
\hline LARPEC & Petiole length (cm) & A & Q \\
\hline IANLAR & Width/length index (ratio) & A & Q \\
\hline INLAM & Leaf blade/petiole index (ratio) & A & Q \\
\hline \multicolumn{4}{|c|}{ Overall first order leaves, at flowering } \\
\hline BAHOJ & Leaf base (cuneate, cordate) & A & At \\
\hline FORHOJ & Leaf shape (oblate, triangular, cordate, lance or round-shaped) & A & At \\
\hline SUHOJ & Leaf surface (flat, waxy, curled) & A & At \\
\hline MAHOJ & Leaf margin (smooth, serrate, deeply serrate) & A & At \\
\hline
\end{tabular}


Table 2: (Cont.) Descriptors used for characterization of wild sunflower populations grown in a common garden

\begin{tabular}{|c|c|c|c|}
\hline Abbreviation & Descriptors (category, units) & Source ${ }^{3}$ & Type $^{4}$ \\
\hline NUHOJ & Leaf number, (n) & 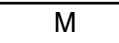 & $Q$ \\
\hline VARHOJ & Leaf shape variation (gradual, abrupt) & A & At \\
\hline DISPHOJ & Leaf arrangement (opposite, alternate) & A & At \\
\hline ANTALL & Anthocyanin in stem and petioles (present, absent) & A & At \\
\hline HOJCAP & Leaves on back of head (present, absent) & M & At \\
\hline NUFLIG & Number of ray flowers $(n)$ & A & Q \\
\hline ANFLIG & Ray width (cm) & A & Q \\
\hline LARFLIG & Ray length (cm) & A & Q \\
\hline PIGFLIG & Ray flower color (other than yellow) & A & At \\
\hline NUFIL & Phyllary (bract) number (n) & A & Q \\
\hline DISPFIL & Phyllary disposition (appressed, loose) & A & At \\
\hline PUFIL & Phyllary tip (acute, acuminate) & A & At \\
\hline PUBFIL & Phyllary pubescente (range from $0,25,50,75$ y $100 \%$ ) & A & At \\
\hline LARFIL & Phyllary length (cm) & A & Q \\
\hline ANFIL & Phyllary width (cm) & A & Q \\
\hline RLARAN & Phyllary Length/Width, (ratio) & A & Q \\
\hline LAREPA & Pale length (seed larger or smaller than pale) & A & At \\
\hline PUBPAL & Pale pubescente (presence, absence) & A & At \\
\hline LOPAL & Pale lobes (presence, absence) & A & At \\
\hline ANPAL & Pale anthocyanin presence (presence, absence) & M & At \\
\hline ANEST & Stigma anthocyanin presence (presence or absence) & M & At \\
\hline DIAMCAP & Head diameter $(\mathrm{cm})$ & M & Q \\
\hline CODIS & Disk flower color (yellow, red) & A & At \\
\hline PEBCAP & Disk white hairs (chaff, presence or absence) & A & At \\
\hline \multicolumn{4}{|c|}{ Life cycle characters: overall population } \\
\hline DTRINIFL & Days from transplant to $10 \%$ flowering $(n)$ & M & Q \\
\hline DINIPLFL & Days from $10 \%$ to $50 \%$ flowering $(n)$ & M & Q \\
\hline DPLFINFL & Days from $50 \%$ flowering to $90 \%$ plants without flowers $(n)$ & M & Q \\
\hline DTRFINFL & Days from transplant to $90 \%$ plants without flowers (n) & M & Q \\
\hline
\end{tabular}

${ }^{3} \mathrm{M}$ : descriptors used in INTA Manfredi Active Germplasm Bank; A: descriptors used in GRINGermplasm Resources Information Network (USDA 2007). ${ }^{4} \mathrm{At}=$ Attribute; $\mathrm{Q}=$ Quantitative.

Phenotypic characterization of wild Helianthus annuus populations was based on 45 descriptors, 22 attributes and 23 quantitative characters. Among them, 14 correspond to those used by the active germplasm bank of the INTA-National Institute of Agriculture in Manfredi, Cordoba, Argentina, while the remaining correspond to those used in the USDA-ARS GRIN-Germplasm Resources Information Network (USDA, 2007). Evaluation characters consisted of seven plant traits, 14 leaf traits, 20 inflorescence traits, and four life cycle traits (Table 2).

Separate ANOVAs were performed for those descriptors which showed variation among and/or within populations. The origins were compared considering all 
the populations nested in the countries, and all populations were compared in an incomplete block design, considering individual values as replicates and the years of evaluation as blocks. To estimate mean values of each quantitative trait, unequal number of plants among populations was corrected using a linear combination of model effects used in ANOVA (LSMEANS), and compared by Tukey-Kramer for $\mathrm{p}$ $£ 0.05$ using procedure GLM of SAS (2002).

\section{RESULTS AND DISCUSSION}

An ANOVA of quantitative characters showed a highly significant model agreement (p£0.01) and type III error sum of squares in the block effect (years) was proportionally small. Within 15 of the analyzed parameters, it represented less than $10 \%$ of that of the treatments, in five it represented 11 to $35 \%$, whereas in the remaining two quantitative descriptors (NUCAP and IANLAR), the proportion of type III error assigned to the year effect was higher than $36 \%$ of the treatment effect.

Table 3: Comparison of 33 characters of wild Helianthus annuus populations from Argentina (ARG) and North America (USA) grown in a common garden at Bahía Blanca. Values in bold correspond to extremes found in populations from Argentina.

\begin{tabular}{|c|c|c|c|c|c|c|c|c|c|}
\hline \multirow{2}{*}{ Traits } & \multicolumn{3}{|c|}{$\mathrm{ARG}^{5}$} & \multicolumn{3}{|c|}{ USA } & \multicolumn{3}{|c|}{ Anova Source } \\
\hline & Means & $\max$ & $\min$ & Means & $\max$ & $\min$ & COUNTRY & ARG & USA \\
\hline$\overline{\mathrm{ALT}}$ & 235.6 & 286.2 & 194.9 & 206.1 & 275.2 & 111.6 & $\star \star$ & $\star \star$ & $\star \star$ \\
\hline DIAMTA & 2.6 & 3.1 & 2.2 & 2.5 & 3.0 & 1.7 & * & ** & ** \\
\hline INCLCAP & 89.4 & 93.6 & 86.6 & 91.2 & 95.3 & 85.4 & ** & $\star \star$ & $\star \star$ \\
\hline NUHOJ & 24.6 & 30.7 & 18.4 & 20.2 & 32.7 & 7.1 & ** & ** & ** \\
\hline NUCAP & 118.7 & 147.3 & 96.2 & 162.8 & 220.5 & 64.6 & $\star \star$ & $\star \star$ & $\star \star$ \\
\hline ANHOJ & 22.4 & 29.0 & 19.8 & 17.5 & 25.4 & 11.1 & ns & * & ns \\
\hline LARHOJ & 25.2 & 31.4 & 21.2 & 20.3 & 27.1 & 15.1 & ** & ** & $* *$ \\
\hline TAMHOJ & 582.3 & 919.2 & 431.5 & 379.2 & 696.4 & 204.5 & ** & $\star \star$ & $\star \star$ \\
\hline LARPEC & 20.5 & 23.9 & 16.8 & 18.2 & 24.7 & 9.1 & ** & ** & $\star \star$ \\
\hline IANLAR & 0.99 & 1.03 & 0.95 & 0.85 & 1.06 & 0.78 & ** & ** & ns \\
\hline ILAMPEC & 1.3 & 1.4 & 1.0 & 1.2 & 1.9 & 1.0 & ** & ** & $\star \star$ \\
\hline NUFLIG & 27.2 & 29.5 & 23.2 & 22.2 & 31.5 & 17.8 & $\star \star$ & ** & $\star \star$ \\
\hline ANFLIG & 1.2 & 1.4 & 1.1 & 1.2 & 1.5 & 1.0 & ns & $\star \star$ & $\star \star$ \\
\hline LARFLIG & 4.2 & 5.1 & 3.5 & 3.8 & 4.6 & 3.3 & ** & * & ns \\
\hline NUFIL & 32.6 & 34.9 & 30.0 & 29.2 & 41.1 & 25.5 & ** & $\star \star$ & $\star *$ \\
\hline LARFIL & 2.4 & 3.0 & 2.0 & 2.1 & 3.0 & 1.7 & ** & ** & $\star \star$ \\
\hline ANFIL & 0.86 & 1.01 & 0.77 & 0.73 & 1.16 & 0.59 & ** & ** & $\star \star$ \\
\hline RLARAN & 2.8 & 3.3 & 2.0 & 2.9 & 3.6 & 2.4 & ns & ** & $\star \star$ \\
\hline DIAMCAP & 4.3 & 5.1 & 3.8 & 3.8 & 5.6 & 2.8 & $\star \star$ & ** & $\star \star$ \\
\hline DTRINIFL & 60.7 & 71.7 & 52.1 & 62.5 & 84.3 & 43.2 & * & ** & $\star \star$ \\
\hline DINIPLFL & 12.1 & 17.3 & 7.6 & 10.0 & 18.3 & 5.0 & ** & ** & $\star *$ \\
\hline DPLFINFL & 51.7 & 111.7 & 30.5 & 52.1 & 75.8 & 24.1 & ** & ** & $\star \star$ \\
\hline DTRFINFL & 124.5 & 175.6 & 106.7 & 124.6 & 149.3 & 96.6 & ns & ** & $\star \star$ \\
\hline
\end{tabular}

${ }^{5}$ Means, minimum and maximum (LSMEANS) of quantitative descriptors and $p>F$ are presented for variation sources among countries and populations in countries. 
The mean and extreme values of the 33 characters are shown in Table 3 . North American and Argentine populations were highly significantly different for 17 of the 23 quantitative characters examined, but showed overlapping ranges of the means for all of traits (Table 3). The North American populations had a higher number of heads, while the average height, leaf number, leaf width and length, head diameter, ray flower and phyllary (bract) number and size were higher in the Argentine populations (Table 3).

The frequency of attribute traits showed a similar continuity between populations from both origins (Table 4). The leaf margin, leaf base and phyllary pubescence had coefficients of variation of more than $35 \%$, but the rest of attribute traits showed low variability, and 11 showed no variability. All the values of Argentine populations were within the range of North American populations, with the exception of leaf margin, anthocyanin in stem, petioles and stigma that slightly exceeded the range.

Table 4: Comparison of attributes traits of wild Helianthus annuus populations grown in a common garden at Bahía Blanca. Values in bold correspond to extremes found in populations from Argentina.

\begin{tabular}{lcccc}
\hline Traits & Mean Frequency & Min & Max & CV \\
\hline PUBTA presence & 1.00 & 1.00 & 1.00 & 0.0 \\
RAMI full branching & 1.00 & 1.00 & 1.00 & 0.0 \\
CAPRIN absent & 0.92 & 0.50 & 1.00 & 11.1 \\
BAHOJ cordate & 0.59 & 0.00 & 1.00 & 50.1 \\
FORHOJ cordate & 0.99 & 0.86 & 1.00 & 2.1 \\
SUHOJ wavy/curled & 0.84 & 0.31 & 1.00 & 19.1 \\
MAHOJ serrate & 0.67 & 0.06 & 1.00 & 38.2 \\
VARHOJ gradual & 1.00 & 1.00 & 1.00 & 0.0 \\
DISPHOJ alternate & 1.00 & 1.00 & 1.00 & 0.0 \\
ANTALL present & 0.78 & 0.49 & 1.00 & 21.3 \\
HOJCAP absent & 0.96 & 0.86 & 1.00 & 4.1 \\
PIGFLIG absent & 1.00 & 1.00 & 1.00 & 0.0 \\
DISPFIL loose & 1.00 & 1.00 & 1.00 & 0.0 \\
PUFIL acuminate & 1.00 & 1.00 & 1.00 & 0.0 \\
PUBFIL 25\% & 0.68 & 0.00 & 1.00 & 35.8 \\
LAREPA seed $<$ pale & 1.00 & 1.00 & 1.00 & 0.0 \\
PUBPAL present & 1.00 & 1.00 & 1.00 & 0.0 \\
LOPAL present & 1.00 & 1.00 & 1.00 & 0.0 \\
ANPAL present & 0.95 & 0.71 & 1.00 & 5.1 \\
ANEST present & 0.98 & 0.83 & 1.00 & 3.5 \\
CODIS red & 0.96 & 0.71 & 1.00 & 5.2 \\
PEBCAP absent & 1.00 & 1.00 & 1.00 & 0.0 \\
\hline
\end{tabular}

The ANOVA indicated highly significant differences for all characters between populations (Table 5). The Argentine populations were different form North American ones, the most similar being BAR and DIA to NM and RAN to IA, which differed 
in two out of 23 analyzed descriptors. All the extreme minimum values for traits were observed in North American populations. Nine maximum values for traits were observed in Argentine populations, but only five were significantly different from North America populations (Table 5). The quantitative attributes showed a continuous distribution between Argentine and North American populations and none differentiated populations from both origins.

Table 5: Quantitative traits differentiation of wild Helianthus annuus populations from Argentina and North America evaluated for three years in a common garden at Bahia Blanca $^{7}$

\begin{tabular}{|c|c|c|c|c|c|c|c|c|c|c|c|c|c|c|c|c|c|c|c|c|c|}
\hline \multirow[b]{2}{*}{$\begin{array}{l}\frac{}{\circ} \\
\frac{0}{0} \\
\frac{\pi}{2} \\
\frac{0}{0} \\
0\end{array}$} & \multicolumn{4}{|c|}{ Plant structure } & \multicolumn{6}{|c|}{ Leaf } & \multicolumn{8}{|c|}{ Inflorescence } & \multicolumn{3}{|c|}{ Cycle } \\
\hline & 尗 & 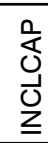 & $\begin{array}{l}\text { 음 } \\
\text { 引 } \\
\text { Z }\end{array}$ & $\begin{array}{l}\frac{0}{\delta} \\
\text { ঠे } \\
\text { z }\end{array}$ & $\begin{array}{l}\text { Oํㅜㄴ } \\
\frac{1}{z} \\
<\end{array}$ & $\begin{array}{l}\text { 울 } \\
\frac{1}{10} \\
\frac{1}{5}\end{array}$ & $\underset{\sum}{\stackrel{0}{1}}$ & $\begin{array}{l}0 \\
\stackrel{u}{0} \\
\frac{1}{5}\end{array}$ & 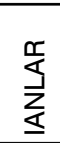 & 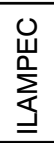 & $\begin{array}{l}\frac{0}{J} \\
\frac{\vec{H}}{2} \\
z\end{array}$ & $\begin{array}{l}\frac{0}{J} \\
\frac{\vec{u}}{z}\end{array}$ & $\begin{array}{l}\frac{0}{3} \\
\frac{u}{\frac{\pi}{4}} \\
\frac{\pi}{5}\end{array}$ & $\frac{\vec{Z}}{2}$ & 这 & 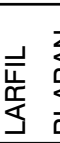 & 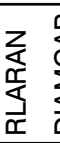 & 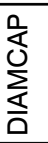 & 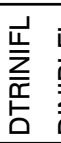 & 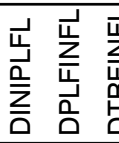 & 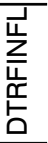 \\
\hline
\end{tabular}

AAL eg ch ac hk bd fi eh gh ef cf ac gi be $f$ e fg $i$ bf ij eh bc fg df CHU gh bg ac ik bd ef fh fh fh bf ac dh ab ab de ce fi cf eg de ij ce cd BAR ce be be fh bd ef $\mathrm{dh}$ eg cd cf $\mathrm{cd} \mathrm{cg}$ ac ae be de bg be fg cd fg df $\mathrm{c}$ RAN cd bg ae fh ac ef be cg bc cf ad gi ab be de ce ch bf fg fh ij cf eg DIA $c d d h a b d g b c$ ef $c f d g$ bc $f \quad c d$ fh $a c$ ad $e$ ce af be $f g$ cd cf $m$ I MAG fg $i$ ac gj cf fi gh gi df cf ad bf be ef e eg $i$ ef $d g c d$ ab $k$ i JCE i gi be jl ce gi gh gi gh df ab fh ab ce ce ce bg bf fg ik bd ce eh RCU i hi ce kl df gi gh hi gh df ac eh ac be e ce ae ad cg ik gh c fi

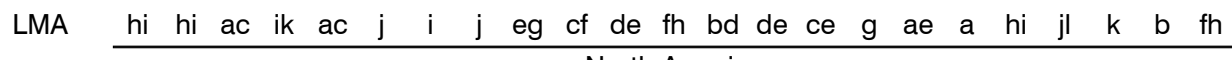
North America

AZ fg hi ae eg cf cf $\mathrm{dh}$ eh ce ad ad ae ac ae be be ad ae bg ik be $k \mathrm{k}$ CA $\quad c g$ fi ac dg $g$ ef $d h$ fh $d f$ be $a d a c a b$ be $a b$ ad bg bf ae fh $f g$ l $k$ $\mathrm{CO} \quad \mathrm{cg}$ gi ac ce $g$ ab ac ad cd ab a ac be de ac ae ei $f$ bg ef bd j gi IL ce ei ac df ab fi eh gi cd $f$ bd $i$ ac ef $f$ g i bf $j$ eh $k$ ce eg IN $\quad$ i gi a $\quad$ l bd $i \quad h$ i fh ef ad eh e de de $i$ hi ab ij $m$ gh ab hi IA cf ad ac hk cd ef be cg bc $f$ ad cg ad ce be df bh be gh jl ij ab ce KS $b$ bh be be $f g$ be ad af bc ae ad bf a ac ad ce di df bf cd bc hi df MT a a e a ab a a a a a ce $a b$ ab a ab ac ab be ad a gh eg a NE i gi ae kl fg fi fh gi $h$ cf ab ae ac ae ce ce ac ac bg $m$ ab a fi NV ce fi be df $g$ ac ad ae ce $a$ ab ad be ae ac ad bh ef ad hj bd cd ce NM c bf ac eg cd cf cf dg ce cf ad cg a ac ce ad af bf bg de cf ij i ND ab a ac bd a be ac ad a cf $f$ ac a ab a de gi df cg bc jk $c$ ab OK fg ei ae gj df fh dg fh eg cf ac ad ac ad ac ad af bf bf l bc hj j SD $a$ ab ae $a b a c a b a b$ ac $a$ ac ef $a b$ a $a$ ac a af $f$ ac ab a gh $a$ TX eg ae be gj eg cf be cg cd df ac ac ad ae ac a a bf a ik cf ij j UT cg ei be dg $g$ cf be bg ce cf $a c$ ab ad be ac ce bh bf bf gi ab $k$ j WY $\quad$ ab ac be ac ac ab a ab ab ad ad a a ad ab ab af ef ab b cf gh bc

${ }^{7}$ ANOVA showed highly significant differences between populations for all considered characters. In each column same letter indicate that means (LSMEANS) for each population are not different for $p=0.05$ according to Tukey-Kramer. See Table 2 for descriptor abbreviations and units. 
The populations showing similarities for one group of descriptors differed by other traits, revealing the existence of different phenotypes (Table 5). The plant structure of plants from DIA, BAR, RAN, CO, IA, IL, NV and NM were in general smaller than those from JCE, RCU, IN and NE. The leaves of RAN, DIA, CA, IA, NM, TX and UT plants were only slightly different than those of the LMA population, while populations from JCE, RCU, MAG, IL, IN, NE and OK had intermediate-sized leaves. Inflorescences of AAL, LMA, IN and IL plants were larger than those of CHU, DIA, AZ, CO, KS, NE, NM, ND, OK and UT. In general, the populations from Argentina showed a different recombination of the traits than observed in North American populations, but there was not any evidence revealing the existence of new genotypes. Plant life cycle showed a more extended range of values separating the majority of the populations, especially the DIA population from Argentina with the longest life cycle of 180 days.

Branching in sunflower is controlled by two complementary dominant genes (Fernández-Martínez and Knowles, 1982) and it predominates in progenies of crosses with wild plants. Among $\mathrm{F}_{1}$ plants from crosses of male-sterile lines with wild $H$. annuus plants, complete branching without (type 4) or with (type 3) main head predominance was observed (Terzić et al., 2006). Descendants of wild plants pollinated by cultivated sunflower would maintain the main head dominance, while the single-headed trait would be lost in a few generations because large seeds are highly vulnerable to predation (Alexander et al., 2001).

Both naturalized annual species in Argentina, $H$. annuus and $H$. petiolaris, can be differentiated through the use of straightforward morphological traits, although discrimination among botanical forms of $H$. annuus is complex because of the extreme morphological variation within the species. Helianthus annuus can be clearly differentiated from $H$. petiolaris based on its wide acuminate phyllaries $(>0.4 \mathrm{~cm})$ and absence of long white hairs in the apex of the main chaff lobe in the center of disks (Seiler and Rieseberg, 1997). The cultivated form H. annuus var. macrocarpus (D.C.) Ckll. can be distinguished from the wild subspecies H. annuus ssp. jaegueri Heiser, H. annuus ssp. lenticularis (Dougl.) Ckll. and ruderal or ornamental $H$. annuus spp. annuus, because of its single head, an involucral bract width over $0.85 \mathrm{~cm}$, yellow-orange ray flowers, and mostly yellow disks (Heiser, 1978).

There were plants with a predominant head (type 3 ) in populations found in LMA, AAL, JCE, RAN, and BAR, though this trait was associated with profuse branching, with more than 32 heads per plant. Individuals with the same type of branching were also observed in North American populations from IN, IL, IA and $\mathrm{ND}$, although the latter two were identified as wild populations from the passport data for the populations. In populations of plants from IN, IL, AAL, MAG and LMA, mean phyllaries width exceed the accepted values for wild subspecies (Heiser, 1978). This could be evidence of introgression with cultivated sunflower in populations from both continents. 
Populations of Helianthus annuus L. naturalized in Argentina showed a profound phenotypic similarity with 17 wild populations from the center of origin in North America. The populations of Helianthus annuus L. naturalized in Argentina presented a high degree of phenotypic variability. However, variability was lower than that in populations examined from North America, but was sufficient to differentiate among populations from both continents.

The phenotypic descriptors were useful to differentiate the Argentine populations and to confirm their wild origin in comparison with North America populations. The populations of Helianthus annuus L. from Argentina and North America showed the presence of some characteristics that would indicate introgression with the cultivated sunflower. At present, it is not possible to clearly differentiate the North American introgressed populations from the Argentine ones. The Argentine populations would not have introgressed traits from cultivated sunflower to the extent and duration of those from the center of origin in North America.

The naturalized wild Helianthus annuus populations established in Argentina represent new biodiversity and are potentially useful genetic resource for broadening the narrow genetic base of cultivated sunflower. An example of this is the life cycle length trait in the Diamante population from Argentina of 180 days and longer, the longest of any population examined.

\section{CONCLUSIONS}

Populations of Helianthus annuus L. naturalized in Argentina showed intense phenotypic similarity with 17 wild populations from the center of origin in North America.

The populations of Helianthus annuus L. naturalized in Argentina presented a high degree of phenotypic variability. Although it was smaller than that in populations from North America and lacks the extremes minimum values, it was enough to differentiate among populations into both groups.

The phenotypic descriptors were useful to differentiate the Argentine populations and to confirm their wild origin in comparison with North America populations. It would support their utility for the evaluation of genetic resources.

The populations of Helianthus annuus L. from Argentina and North America showed the presence of some characteristics that would indicate introgression with the cultivated sunflower. It would turn very complex to complete differentiation with the cultivated form.

Helianthus annuus populations established in Argentina could be considered a differentiated genetic resource, containing new combinations of the phenotypic traits presents in populations of North America. 


\title{
ACKNOWLEDGEMENTS
}

\author{
To National Research Council of Argentina (CONICET) for a fellowship \\ to AP. To the Fundación Carolina, Spain for a fellowship to MC. We are \\ grateful to Drs. Ignacio Romagosa and Luis Torres from Centro UdL- \\ IRTA, Lleida, Spain, for assistance with statistical data analyses. This \\ research was supported by grants ANPCYT-PICT 08-9881 and UNS-PGI \\ $24 A 106$.
}

\section{REFERENCES}

Al-Khatib, K., Baumgartner, J.R., Peterson, D.E. and Currie, R.S., 1998. Imazethapir resistance in common sunflower (Helianthus annuus). Weed Sci. 46: 403-407.

Alexander, H.M., Cummings, C.L., Khan, L. and Snow, A.A., 2001. Seed size variation and predation of seeds produced by wild and crop-wild sunflowers. Am. J. Bot. 88: 623-627.

Bauer, H.A., 1991. Cuarenta años en el mejoramiento del girasol (Helianthus annuus L.) en Argentina 1947-1987. Helia 14(14): 63-68.

Bhattacharjee, R., Khairwal, I.S., Bramel, P.J. and Reddy, K.N., 2007. Establishment of a pearl millet [Pennisetum glaucum (L.) R.Br.] Core collection based on geographical distribution and quantitative traits. Euphytica 155: 35-45.

Burke, J.M., Tang, S., Knapp, S.J. and Rieseberg, L.H., 2002. Genetic analysis of sunflower domestication. Genetics 161: 1257-1267.

Cantamutto, M., Poverene, M. and Peinemann, N., 2008. Multi-scale analysis of two annual Helianthus species naturalization in Argentina. Agriculture, Ecosystems and Environment 123: 69-74.

Fernandez-Martinez, J. and Knowles, P.F., 1982. Genética de la polifloría en el girasol silvestre Helianthus annuus L. Anal INIA Serie Agrícola 17: 25-30.

Heiser, C.B., 1954. Variation and subspeciation in the common sunflower, Helianthus annuus. The American Midland Naturalist 51: 287-305.

Heiser, C.B., 1978. Taxonomy of Helianthus and origin of domesticated sunflower. In: Carter, J. (ed.) Sunflower Science and Technology. Madison, USA, pp. 31-53.

Hu, S., Yu, C., Zhao, H., Sun, G., Zhao, S., Vyvadilova, M. and Krucera, V., 2007. Genetic diversity of Brassica napus L. germplasm from China and Europe assessed by some agronomically important characters. Euphytica 154: 9-16.

International Seed Testing Association, 2004. Germination. In: ISTA (ed.) International Rules for Seed Testing. Zürich, Switzerland.

Maxted, N., Ford-Lloyd, B.V., Jury, S., Kell, S. and Scholten, M., 2006. Towards a definition of a crop wild relative. Biodiversity and Conservation 15: 2673-2685.

Poverene, M., Cantamutto, M., Carrera, A., Ureta, M., Salaberry, M., Echeverria, M. and Rodriguez, R., 2002. El girasol silvestre (Helianthus spp.) en la Argentina: Caracterización para la liberación de cultivares transgénicos. RIA 31: 97-116.

Putt, E.D. and Sackston, W.E., 1957. Studies on rust. I. Some sources of rust resistance. Can. J. Plant Sci. 37: 43-54.

Rawashdeh, N.K., Haddad, N.I., Al-Ajlouni, M.M. and Turk, M.A., 2007. Phenotypic diversity of durum wheat (Triticum durum Desf.) from Jordan. Genetic Resources and Crop Evolution 54: 129-138.

SAS, 2002. SAS Institute Inc. 9.1.3. Cary, NC: SAS Institute Inc., 2002-2005.

Schilling, E.E., 2006. Helianthus. In: Flora of North America Editorial Committee (eds.) Flora of North America North of Mexico Vol 21. New York and Oxford.

Schneider, A.A. and Miller, J.F., 1981. Description of sunflower growth stages. Crop Sci 21: 901-903.

Seiler, G.J., 1983. Effect of genotype, flowering date, and environment on oil content and oil quality of wild sunflower seed. Crop Sci. 23: 1063-1068.

Seiler, G. and Rieseberg, L., 1997. Systematics, Origin, and Germplasm Resources of the Wild and Domesticated Sunflower. In: Schneiter, A. (ed.), Sunflower Technology and Production. Madison, Wisconsin, USA, pp. 21-65. 
Soleimani, V.D., Baum, B.R. and Johnson, D.A., 2007. Analysis of genetic diversity in barley cultivars reveals incongruence between S-SAP, SNP and pedigree data. Genetic Resources and Crop Evolution 54: 83-97.

Terzić, S., Zorić, M. and Miladinović, F., 2006. Phenotype variability and inheritance of plant height and branching in $\mathrm{F}_{1}$ generation of sunflower. Helia 29(44): 87-94.

USDA, ARS, National Genetic Resources Program. Germplasm Resources Information Network - (GRIN). [Online Database] National Germplasm Resources Laboratory, Beltsville, Maryland. http://www.ars-grin.gov/cgi-bin/npgs/html/crop.pl?79 Cited November 2007.

\title{
DIVERSIDAD FENOTÍPICA EN Helianthus annuus SILVESTRE DE ARGENTINA
}

\author{
RESUMEN
}

Poblaciones naturalizadas de Helianthus annuus silvestre se han dispersado a partir de su introducción desde el centro de origen, en Norteamérica. La caracterización fenotípica basada en 45 descriptores morfológicos y fenológicos de nueve poblaciones procedentes de diferentes regiones geográficas de Argentina y 17 poblaciones de USA, provistas por el US Department of Agriculture germplasm bank en Ames, Iowa fue realizada cultivándolas en un campo experimental. Las poblaciones silvestres de Argentina reflejaron parte de la variabilidad fenotípica de las poblaciones provenientes del centro de origen, aunque mostraron adaptación a condiciones locales, lo que permitió la diferenciación entre poblaciones de cada continente. Todos los caracteres mostraron un rango continuo de variación, con la mayoría de los valores extremos observados en las poblaciones Norteamericanas. Las poblaciones que mostraron similaridad para un grupo de caracteres difirieron en otros, revelando la existencia de diferentes fenotipos. Las poblaciones de Helianthus annuus establecidas en Argentina podrían ser consideradas un recurso genético diferente, con nuevas combinaciones de caracteres presentes en las Norteamericanas y algunos ausentes en estas últimas, como el largo de ciclo de Diamante de más de 180 días, el periodo más largo entre las poblaciones estudiadas.

\section{DIVERSITÉ PHÉNOTYPIQUE DANS Helianthus annuUs SAUVAGE DE L'ARGENTINE}

\author{
RÉSUMÉ
}

Des populations naturalisées de Helianthus annuus sauvage se sont dispersées à partir de son introduction depuis le centre d'origine, en Amérique du Nord. La caractérisation phénotypique basée sur 45 descripteurs morphologiques et phénologiques de neuf populations originaires de différentes régions géographiques de l'Argentine et de 17 populations des États-Unis, fournies par le banc de germoplasme du Département d' Agriculture d'Amérique du Nord à Ames, Iowa, a été réalisée en les cultivant dans un champ expérimental. Les populations sauvages de l'Argentine ont exhibé une partie de la variabilité phénotypique des populations procedentes du centre d'origine, bien qu'elles ont montré d'adaptation aux conditions locales, ce qui a permis la différenciation entre les populations de chaque continent. Tous les caractères ont montré un rang de variation continu, avec la plupart des valeurs extrêmes observées dans les populations Nord-américaines. Les populations qui ont 
montré similitude pour un groupe de caractères ont différé pour les autres, en révélant l'existence de différents phénotypes. Les populations de Helianthus annuus établies en Argentine pourraient être considérées comme une ressource génétique différente, avec de nouvelles combinaisons de caractères présents dans les populations Nord-américaines et certains caractères absents dans celles-ci, comme la longueur du cycle dans Diamant de plus de 180 jours, la période la plus longue entre les populations étudiées. 
